\title{
WORK IN PROGRESS
}

\section{An Overlooked Colonial English of Europe: the Case of Gibraltar}

\begin{abstract}
Gibraltar, popularly known as "The Rock", has been a British overseas territory since the Treaty of Utrecht was signed in 1713. The demographics of this unique colony reflect its turbulent past, with most of the population being of Spanish, Portuguese or Italian origin (Garcia 1994). Additionally, there are prominent minorities of Indians, Maltese, Moroccans and Jews, who have also continued to influence both the culture and the languages spoken in Gibraltar (Kellermann 2001). Despite its status as the only English overseas territory in continental Europe, Gibraltar has so far remained relatively neglected by scholars of sociolinguistics, new dialect formation, and World Englishes. The paper provides a summary of the current state of sociolinguistic research in Gibraltar, focusing on such aspects as identity formation, code-switching, language awareness, language attitudes, and norms. It also delineates a plan for further research on code-switching and national identity following the 2016 Brexit referendum.
\end{abstract}

Keywords: Gibraltar, code-switching, sociolinguistics, New Englishes, dialect formation, Brexit.

\section{Introduction}

Gibraltar is located on the southern tip of the Iberian Peninsula and measures just about 6 square kilometres. This small size, however, belies an extraordinarily complex political history and social fabric. In the Brexit referendum of $23^{\text {rd }}$ of June 2016, the inhabitants of Gibraltar overwhelmingly expressed their willingness to continue belonging to the European Union, yet at the moment it appears that they will be forced to follow the decision of the British government and leave the EU (Garcia 2016). Such a turn of events may lead to numerous changes in the sociopolitical structure of the community, which has never been stable for any significant length of time.

The present paper seeks to introduce readers to Gibraltar's turbulent history and provide a review of the current state of sociolinguistic research concerned with identity formation, code- 
switching, and language awareness, attitudes, and norms in Gibraltar. It also lays out suggestions for further research, and urges sociolinguists and those interested in language contact and New Englishes to pay closer attention to the processes currently taking place in this unique British colony.

\section{Gibraltar past and present}

\subsection{Brief overview of external history}

Before one delves into any consideration of the complex sociolinguistic situation of Gibraltar, a brief historical overview is necessary. Gibraltar came into the British hands in 1704, and has been officially British since 1713, which marks the date of the Treaty of Utrecht. The history of Gibraltar is, however, much longer than the period of the British settlement. Since earliest times, Gibraltar has attracted much attention from different races, nations and cultures due to its strategic geographic position. It is an apparent fact that dominance over Gibraltar grants dominance over the Straits commanding the entrance from the Atlantic to the Mediterranean (Levey 2008). After taking control of it in 711, the Umayyad Emirate and its successor states controlled Gibraltar all way until 1492, when it was captured in the name of the Duke of Medina Sidonia and proclaimed part of Spain by Queen Isabella. A long-lasting period of stability arrived in Gibraltar, which only came to a halt with the Spanish War of Succession. The war had its onset in the death of King Charles II in 1700, leaving no heir to his throne. Two contestants emerged, namely Duke Philip of Anjou, who was a protege of Louis XIV of France, and Archduke Charles of Austria. Fearing the threat to their interests of Bourbon rule over both France and Spain, Britain decided to support Austria and the Netherlands, which led to an Anglo-Dutch fleet conquering Gibraltar in 1704. Officially, "the Rock" was taken over in the name of the Archduke Charles of Austria; however, Britain unsurprisingly saw an immense strategic potential in this small piece of land (Constantine 2013).

Following the capture, a decade of political conflict and unrest spread around Europe. This ended in 1713 with the aforementioned Treaty of Utrecht which, in article X, formally declared Gibraltar a British property: "The Catholic King does hereby, for himself, his heirs and successors, yield to the Crown of Great Britain the full and entire propriety of the town and castle of Gibraltar, together with the port, fortifications, and forts thereunto belonging; and he gives up the said propriety to be held and enjoyed absolutely with all manner of right for ever, without any exception or impediment whatsoever."

Since that day, Spanish governments have on numerous occasions tried to undermine the significance of the Treaty, but all those efforts have so far been to no avail. Initially, the Spanish thought the enactment of Article X would be temporary; therefore, a nucleus of the Spanish population remained in Gibraltar, at the same time providing a solid foundation for a new society under construction. The final Spanish effort to take back Gibraltar took place between 13th September 1779 and 12th March 1783, during the Anglo-French conflict accompanying the American War of 
Independence. The fortress was defended by General George Eliott and around 5,500 to 7,000 men under his command, during what came to be known as the Great Siege of Gibraltar (Kramer 1986). The Gibraltar of the $19^{\text {th }}$ century saw three immense changes: its status was altered from merely a military outpost to a British Crown Colony, it gained importance due to the opening of the Suez Canal, and an Alien Order in Council was established in order to limit immigration to British subjects (Constantine 2013). The last development engendered a substantial wave of immigration from Malta and India. Nevertheless, there were numerous Spanish citizens commuting daily across the border to fill their professional positions. The distinction between the British and the "others", which the UK government insisted on, became increasingly difficult to maintain over time. Ethnic differences were almost of no importance in Gibraltar from the very onset, as the colony was of a multiethnic nature. Many Spanish citizens also managed to receive permanent residence in Gibraltar, despite the laws in force, e.g. through marriage with British nationals (Constantine 2013).

The beginning of the $20^{\text {th }}$ century was rather uneventful in Gibraltar, as Spain remained neutral during the First World War and no apparent threat to Gibraltar was present. More power was secured by the citizens of Gibraltar, as in 1921 elections took place and four positions on the City Council were filled by native Gibraltarians (Kramer 1986). Gibraltar also provided shelter for numerous Spanish refugees during the Spanish Civil War, when even The Gibraltar Chronicle was published with special war editions in Spanish (2008).

The Second World War initiated immense social and linguistic changes, as Gibraltar played a major role in the conflict, serving as a base for British naval convoys venturing to Malta. Many Gibraltarians were forced to leave their homeland and were relocated either to the United Kingdom or other Crown Dependencies, such as Jamaica. They were fully-immersed in the British culture and education, and some people were actually exposed to English as a native language for the first time (Constantine 2013). Both local and British identity were fostered, and important political changes were inspired (Levey 2008). The first political party of Gibraltar was formed, as many people felt mistreated by the British, since the repatriation process was far from perfect, and demanded more independence. The Association for the Advancement of the Civil Rights dominated the political scene of Gibraltar for the next forty years (Constantine 2013).

The 1960s began with the intensification of tensions between Gibraltar and Spain. Gibraltarians decided to organize a referendum to decide which side they would prefer to find themselves on, be it Spanish or British. A total of 12,182 people took part in the voting process, and just 44 opted for coming under Spanish rule. As Spanish pride was deeply hurt, in 1969 the border between Gibraltar and Spain was closed and remained so for the next 13 years. This radical step, which was supposed to crash the Rock both economically and morally, was implemented overnight and barred all cross-border activity. Contrary to the Spanish vision, however, the plan backfired, and the neighbouring Spanish villages suffered the most as Gibraltar continued to flourish (Levey 2008; Constantine 2013). Interactions with the native Spanish populations were limited and distrust towards the Spanish government peaked, leading to the decline of the Spanish language among Gibraltarians. Despite the blockade being lifted in 1982 and rekindling of a significant amount of cross- 
border movement, the earlier state of contact with and proficiency in Spanish was never restored (Levey 2008).

\subsection{Gibraltar today}

The Rock today is inhabited by around 30,000 people. Its major ethnic groups include Spanish, Italian, English, Portuguese, and North African (United Nations 2016). Additionally, there are prominent minorities of Indians, Maltese, Moroccans and Jews, who have also continued to influence both the culture and the languages spoken in Gibraltar (Kellermann 2001).

Such a mixture of peoples, together with the peculiar and long troublesome geographical location of Gibraltar, raises many questions of language and identity, as people who live on the same territory for a prolonged time tend to develop shared values and interests, and eventually a sense of common local identity (Anderson 1991). Such groups often develop distinct ways of speaking which differentiate them from other geographical or social groups, thereby evolving into a speech community (Labov 1963; Milroy 1987; Melancon 2000; Milroy and Gordon 2003). This is especially apparent in the evolution of so-called "New Englishes", as one can see for example in the case of Australia, where following independence the variety of English spoken there received official recognition and now constitutes a standard of its own (Moore 2008).

The official language of Gibraltar is English, which is used both in formal and educational settings; however, due to its complicated past and the proximity of Spain, Spanish is also widely spoken. Although it does seem to possess features differentiating it from the Andalusian speech forms of the neighboring campo region, it continues to belong to the group of Andalusian dialects.

It is often claimed, however, that the most distinctive language spoken in Gibraltar is the socalled Yanito, which was defined by Levey (2008) as “(...) an Andalusian dominant Spanish form of oral expression which integrates mainly English lexical and syntactic elements as well as some local vocabulary". This definition implies that Yanito is a form of a code-switched discourse. The ability to switch easily between English and Spanish has often been commented on, including the near impossibility of spotting the moment at which Gibraltarians switch from one language to the other (Levey 2008). In this respect, Gibraltarians have even been compared to bilingual Puerto Ricans who live in the United States, but the social roles of code-switching in the two communities seem to be quite different (Moyer 1993).

The present-day sociopolitical situation of Gibraltar has been made even more complicated by the Brexit referendum of 2016, in which a whopping 96\% of eligible Gibraltarians opted to remain in the European Union. Despite such an overwhelming victory for the "Remain" camp, it seems that Gibraltar will be forced to secede from the Union hand in hand with the United Kingdom against the will of the overwhelming majority of its inhabitants. As one may suspect, this has brought much unwanted uncertainty over the future of Gibraltar's economy, laws affecting the movement of people, and even political status. 


\section{History of research on the linguistic situation in Gibraltar}

Despite such a wealth of research possibilities and its accessible location, Gibraltar has so far remained relatively neglected by scholars of sociolinguistics, new dialect formation, and World Englishes. The only specialist studies devoted to the linguistic situation of Gibraltar are Krammer (1986), Moyer (1993), Kellermann (2001), and Levey (2008), and of these, only Levey 2008 focuses on Gibraltarian English as a new colonial variety. The status of Gibraltar as a blank spot on the map of postcolonial Englishes may be illustrated by its absence from such authoritative recent references on world and postcolonial Englishes as Kortmann and Schneider (2008) or Schreier et al. (2009). It is, therefore, important to pay closer attention to the work which has already been done on Gibraltar in order to suggest and delineate further research needs of Gibraltar.

\subsection{Johannes Kramer, Spanish and English in Gibraltar (1986)}

Kramer opens his study of Gibraltar by specifying three central issues:

1. the historical background of Gibraltar;

2. the educational system of Gibraltar;

3. the effects of the co-existence and intermingling of English and other languages spoken in Gibraltar, in particular Genoese, Andalusian Spanish, and Italian.

He also attempts to tackle the issue of English-Spanish bilingualism and "Gibraltar's Spanish dialect called Yanito".

The overview of the history of Gibraltar, which spans the period between 1704 and 1969, is thorough, well-researched, and provides a reader with a sufficient grasp of the colony's external and social history. The following chapter, devoted to the educational system of Gibraltar, is based completely on the work of a young Gibraltarian which, as the author laments, remained unpublished. The focus here is mainly on the role of religion and religious organizations on education. Additionally, as Kramer pointed out, Gibraltar still remained a military outpost at the time of writing, centuries after its capture by the British, and thus it had no official educational bodies (Traverso 1980, quoted in Kramer 1984:31).

The chapter on the linguistic situation of Gibraltar is the longest in the book and begins by introducing descriptions of the separate languages involved in language contact. In comparison with the others, the Genoese variety of Italian seems to be relatively neglected, with only a brief mention of its origins. The influence it possibly had on the linguistic mix in earlier times remains unexplored. As remnants of the language can be found only in religious rites, it is assumed that Genoese disappeared due to immense pressure it experienced from Spanish (Kramer 1986).

The reasons for the importance of Spanish are investigated briefly and seem to boil down to the following:

1. the slow influx of Spanish speakers into Gibraltar despite law against such movements of peoples;

2. adstratum influence due to the proximity of Spain; 
3. trade with Spain, communication with the Spanish-speaking workforce, and intermarriage. Notably, the existence of a Romance-based pidgin is presupposed for the 19th century (Kramer 1986).

As was the case with many British colonies, English was the language of the military and the British soldiers who occupied Gibraltar. No merit was seen in learning local languages, and thus the soldiers refrained from doing so. It is, however, probable that religion rather than language was the major deterrent to acquiring Spanish. Most soldiers were Protestants, while the speakers of Spanish were usually Catholics. The first locals to learn English as a second language were the Jews, who having suffered persecution in Spain felt no affiliation towards Spanish and therefore switched rapidly to English without ever looking back. They oftentimes served as translators for the military staff (Kramer 1986).

The motivation for the rise of English seems to be of a dual nature. Firstly, an external motivation arose due to the fact that speakers began to realize the necessity to have a decent command of English to land a well-paid job. Secondly, an internal motivation sprang from the growing distrust of Gibraltarians towards Spain.

A dictionary of Yanito presented in Kramer's study is taken directly from Manuel Sevilla's Diccionario Yanito, except that it has been subdivided into separate semantic fields. Kramer thereupon embarks on a presentation of the sound system of Yanito and laments the absence of Gibraltarian Spanish from Spanish dialectology, as the dialect simply seems to be nonexistent in the relevant literature. Having collected some vocabulary items, he compares them with the closest investigated regions, namely Tarifa and Manilva; the comparison is supplemented by an approximate phonetic transcription.

Interestingly, there seems to be evidence both supporting and disproving the hypothesis about Gibraltar's place among the Spanish dialects of Andalusia. Dialectal realizations which bear out the hypothesis are, for example:

1. Yeísmo - pronouncing $l l$ as $[\mathrm{y}]$ and other sounds derived from it;

2. persistence of aspirate $/ \mathrm{h} /$;

3. partial assimilation of such consonant clusters as /gw/ and /bw/;

4. disappearance of intervocalic/d/ (Kramer 1986).

Among the features which argue against Gibraltarian Spanish as an Andalusian dialect are, for example:

1. lack of voiceless dental fricatives;

2. absence of velarisation of $/ \mathrm{n} /$;

3. nasalisation of the vowel preceding /n/ (Kramer 1986).

It is argued that these features may stem from the language-contact situation between Spanish and Genoese. This claim seems dubious, however, as the Genoese-speaking population was rather small in the early days of the colony and, additionally, most of the features may be ascribed to English-Spanish language contact (Kellermann 2001). 
The examples of Yanito code-switching provided in Kramer's work come from Calentita, which is a column published in a Gibraltarian newspaper Panorama. This column presents recent news in a commentary which is done by two typical housewives - Cloti and Cynthia.

Onomastic issues are also tackled, namely the etymology of the words Yanito and Gibraltar. Yanito is believed to come from Latin plānus (Spanish llano), which means 'flat'. It is pointed out that the word is often used to describe a spoken dialect in contrast to the written standard, as for example in the case of northern German (Kramer 1986). As is well known, the name Gibraltar originated from Arabic jabal Tariq 'Tariq's Mountain' and was given to the territory in the honor of the Berber leader who captured Gibraltar in 711, Tariq Ibn Ziyad (Kramer 1986).

To conclude, English and Spanish in Gibraltar is a landmark first attempt at describing and analysing the complex linguistic situation in Gibraltar. As such, it is an important achievement, even if the study at times comes across as haphazard and erratic in its methodology. In general, it is valuable today more as a guide for further research than as an empirical study. However, the work does successfully indicate gaps in the existing state of knowledge and identify problems for future research (Kellermann 2001).

\subsection{Melissa G. Moyer, Analysis of Code-Switching in Gibraltar (1993).}

Moyer's research plan, at first, had been to learn more about the linguistic situation in Gibraltar, but in the end the research question was narrowed down to an analysis of the code-switching phenomenon in Gibraltar. The speech community of Gibraltar is described, and the decision is made to treat it as an idealized unit for the sake of the study. Code-switching is defined as a communicative act between two proficient bilinguals or to be more exact: "where lexical elements from two languages are combined structurally in a single sentence or larger unit” (Moyer 1993:69).

The data was collected using the interview form, along with language diaries and questionnaires. However, the greatest challenge remained the observer's paradox. This was tackled by providing each recording with an appropriate commentary made by the researcher. Of a total of 21 recordings, 16 were selected as they represented a wide range of settings and situations. It is also crucial to mention that although 50 language diaries were administered, only 11 of those were turned in. In the diaries, the participants had to choose their dominant language (English, a mix of English and Spanish, a mix of Spanish and English, or Spanish) in the domains of work; telephone conversations; streets, and stores; and home. Six out of the investigated group tended to use more English than Spanish, and the remaining five more Spanish than English. The analysis of the domains indicates that Spanish is more heavily used in informal contexts (home and street), but interlocutors also need to be considered when determining the language of any conversation.

Moyer's study finds that code-switching is the most common form of linguistic form of expression except for the domain of telephone conversations. Usually the code-switched discourse is Spanish-dominant; however, it is noted that an English-dominant mix is often used to assert Gibraltarian identity. Therefore, code-switching or, in other words, Yanito may claim some form of covert prestige. The group, however, was relatively homogeneous in terms of social background, 
as only two never continued their education in Britain, and just one was not a Roman Catholic. It thus needs to be underscored that such a sample is in no way representative of the population of Gibraltar as a whole. The thesis claims that the representatives of lower classes of the community show more local identity and tend to communicate more in Spanish and a mixture of Spanish and English, but this conclusion is based entirely on impressionistic observation.

The recordings are analyzed by means of discourse analysis, for which a wide framework is employed:

1. discourse strategies accomplished by a switch;

2. the search for nonliteral meaning in both macro- and micro-sociolinguistic realities.

Four different code-switching patterns in conversations are identified:

1. alternative use of two language by different participants;

2. combination of different semantic constituent within one sentence;

3. insertion of individual lexical items;

4. insertion of ritualized expressions.

To develop a theoretical framework which could account for meaningful and non-meaningful code-switching in relation to group and society, Moyer proposes the following scheme:

Table 1. Code-switching: Individual, Social and Interactional meaning (adopted from Moyer 1993: 233)

\begin{tabular}{|l|l|l|}
\hline \multirow{2}{*}{$\begin{array}{l}\text { Individual speaker } \\
\text { production: }\end{array}$} & \multicolumn{2}{|l|}{ Meaning of code-switching: } \\
\cline { 2 - 3 } & \multicolumn{2}{|l|}{ Interactional meaning } \\
\hline Passive switching & $\begin{array}{l}\text { RVI } \\
\text { Responsive code-switching } \\
\text { in verbal interaction }\end{array}$ & $\begin{array}{l}\text { RSD } \\
\text { Responsive code-switching } \\
\text { in a social domain }\end{array}$ \\
\hline Active switching & $\begin{array}{l}\text { IVI } \\
\text { Initiative code-switching } \\
\text { in verbal interaction }\end{array}$ & $\begin{array}{l}\text { ISD } \\
\text { Initiative code-switching in } \\
\text { a social domain }\end{array}$ \\
\hline
\end{tabular}

In this model, RVI and RSD represent passive code-switching, as the speaker is simply reacting to the previous utterance. This can be seen as a sign of solidarity in the RVI type or orienting oneself towards a certain societal domain in the case of the RSD type; for example, Gibraltarians tend to automatically switch to English in the domains of government and education. Code-switching discourse sometimes also seems to constitute the unmarked choice in verbal interactions (Moyer 1993). The IVI and ISD types of switches may be considered active, as the speaker takes the initiative either to achieve a certain discourse function and negotiate social relations (IVI), or establish a switch towards an interaction within a certain domain (ISD; Moyer 1993). 
Within the wider sociolinguistic literature, numerous researchers have tried to establish constraints on code-switching, such as Muysken (1995), Poplack and Meechan (1995). However, their analyses fail to account for all the instances of code-switching observed in Gibraltar as some examples of sentential code switching cannot be explained as many of them are far from being ungrammatical due to the fact that they follow the rules of both English and Spanish grammars (Moyer 1993).

The data collection which led to writing of the thesis is to be praised. It is, however, problematic in that the selection of subjects seems to have a strong middle-class bias. The author, unfortunately, fails to provide us with a more detailed look at her findings. Nevertheless, Moyer's research is an important step towards uncovering the complexity of the linguistic situation in Gibraltar, and it provides important insight into the Gibraltarian speech community of the early 1990s.

\subsection{Anja Kellerman, A New New English: Language, Politics, and Identity in Gibraltar (2001)}

The aim of Kellermann's thesis was to examine language attitudes, language use, and language form in contemporary Gibraltar. To meet these research objectives, 70 interviews were conducted over three visits to Gibraltar in 1991 and 1992. Three major groups can be specified in the data, namely:

1. Gibraltarian teachers;

2. a small number of UK teachers, who served as a control group;

3. a community sample (Kellermann 2001).

The groups were sprinkled with a sample of the population which worked for the Gibraltar government: party leaders, employers, and educational experts (Kellermann 2001). Thus, an extensive spoken Gibraltarian English corpus was created, which could be subjected to both qualitative and quantitative analysis.

Over the course of several generations, the society of Gibraltar has become a multinational one for a number of reasons. English is now the main language used in Gibraltar. Surprisingly, however, it was not imposed by the colonial power of the United Kingdom, but was seemingly voluntarily adopted by the population of Gibraltar. English began serving as an identity marker, and the shift away from Spanish could be understood as an "act of identity" (LePage \& Tabouret-Keller 1985). It has gone a long way from being just the language of international communication to, in the end, the language of local communication as well. Additionally, the socioeconomic value of English is an important factor which contributed to Gibraltarians abandoning their first language in favor of English.

The administered language attitude survey seems to indicate that there continued to exist a general distrust towards Spain. The informants saw themselves on the spectrum between British and Gibraltarian, with $43 \%$ being pro-British, 23\% feeling both British and Gibraltarian, and 34\% considering themselves simply Gibraltarian. There was no integrative attitude present towards Spain. The majority of speakers also detest being depicted as Spanish, but do not mind being seen as Brit- 
ish. The thesis suggests that an anti-Spanish complex runs deep in the society, and it remains to be seen if it is there to stay. Interestingly, Yanito seemed to enjoy quite a high level of covert prestige but was stigmatized as far as overt prestige was considered, the assumption being that this may be due to the aforementioned distrust towards Spain and Spanish (Kellermann 2001).

Owing to the growing indifference of Britain towards Gibraltar (illustrated by the sovereignty referendum offered by the United Kingdom in 2002 to share the territory of Gibraltar with Spain), the citizens began striving for more independence and the right to self-determination. This, in turn, gave rise to a local Gibraltarian English identity. The English part of the identity is, however, slowly becoming weakened, with the local Gibraltarian part continuously gaining strength.

The institutionalization of English and the adoption of British English as the pronunciation model, combined with the fact that for many educators English was a second language (and, therefore, their pronunciation diverged from that of the model), has given rise to a new variety, Gibraltarian English. A general tendency may be observed to opt for intermediate consonantal and vocalic forms which exist neither in British English nor in Spanish. There also exists a continuum ranging from pronunciations closer to the British model to highly divergent variants. This could serve as evidence that the normalization process is currently in progress, of which the end result seems to be located close to the British English standard, without entirely conforming to it.

The thesis is marked by great academic rigor and extensiveness of the data collection and analyses. It still remains to be investigated, however, whether the tendency towards the standardisation of a new Gibraltarian variety of English is still under way, as one must remember that the data used in the research was collected in the early 1990s and, contrary to what Kellermann claimed, could already have been somewhat outdated at the time of publication.

\subsection{David Levey, Language Change and Variation in Gibraltar (2008)}

According to the author, the study was undertaken due to all the recent developments in the field of sociolinguistics in Europe at large. Its main objective was to analyze the use of English among adolescent speakers in Gibraltar and compare them with the patterns found in older generations.

The study was undertaken in three middle and two secondary schools. A total of 72 Gibraltarians (38 between the ages of 13-19 and 34 between the ages of 9-12) were selected, and from them a 40 -hour long audio corpus was created. Social variables such as age, sex, ethnicity, and class are considered. The steps taken to minimize the observer's paradox included, for example, building friendly relationships with the subjects beforehand and postulating introductory questions to establish a level of rapport. The interviewees also remained largely uninformed about the objective of the research, so that that knowledge would not interfere with their linguistic performance. The tasks were:

1. personal information questions;

2. reading wordlists;

3. translation wordlists;

4. interviews on language attitudes, preference, and competence (Levey 2008). 
The results of Levey's study indicate that Yanito and Spanish seem to be losing ground due to the increasing dominance of English as the first language, as the latter seems to have overtaken the Home domain. A growing number children are brought up solely with English spoken to them. Such a turn of events is attributed to the border blockade of 1969 (see above, \$1).

A conspicuous divide is found between the preadolescents and adolescents, with the former using more English than the latter. This may either be indicative of a language shift in progress or simply reflect a momentary, age-graded phenomenon, as younger pupils tend to be more impressionable and, therefore, influenced by their teachers and parents. Interestingly, Yanito was found to be spoken with older siblings, but English with younger ones (Levey 2008).

With respect to class, upper-middle class and middle-class children opt for using English as their main mode of communication, while those from lower social classes tend to use Spanish. Social networks also come into play and seem to correlate with the Jewish, Indian, and Moroccan ethnic groups, with the first two priding themselves on the best command of English. It is also pointed out that the autochthonous Gibraltarians seem to operate according to distinct patterns, as they exhibit the highest level of Spanish maintenance and the most considerable generational shift to English. In contrast, gender was deemed to have no effect (Levey 2008).

As far as phonetic realizations are concerned, Gibraltarian English seems to be approaching the British English standard more than previous studies suggested. It is not, however, claimed that this is the variety that the speakers fully aim at. Typical features of Spanish substratum influence, such as $\int / \mathrm{t} \int, 3 / \mathrm{d}_{3}, \mathrm{j} / \mathrm{d}_{3}$, or the KIT/FLEECE and TRAP/STRUT/BATH mergers, were no longer found. Young Gibraltarians also exhibit certain substandard features found in other English-speaking communities too, such as T-glottaling and TH-fronting, but Levey stresses that they cannot be assessed and judged using the same methods as in the United Kingdom, as their social meaning and context differ greatly.

It is suggested that Gibraltarian English may further assimilate to the British standard due to the positive attitude towards the United Kingdom among the young. Additionally, both preadolescents and adolescents often made remarks that suggest that they consider the local vernacular to be a limitation or defect on the part of a speaker, rather than a legitimate dialect. This shift in progress is also considered an "act of identity", but one that emphasizes the British national and linguistic identity of Gibraltarians. Nevertheless, the paper concludes that the further development of English in Gibraltar may not necessarily follow this trend, and therefore that more research is required.

The author contributed a sound piece of scholarly work on the phonetics of the current state of Gibraltarian English. Perhaps the only faults of the study, but unfortunately significant ones, are that: 1) it is focused only on the phonetics of Gibraltarian English, and 2) the issue of code-switching is almost entirely omitted from discussion, as the author treats "English" and "Spanish" as discrete, unitary linguistic systems. One can only agree with Levey, however, that more research is necessary to determine the long-term trajectory of language shift and attitudes among speakers of Gibraltarian English and their relation to changing self-identification. 


\section{Conclusions and goals of future research}

It is necessary to note that despite a significant wealth of research possibilities, Gibraltar has so far failed to attract much interest from the broader scientific community, including sociolinguistics or sociologists. Weston (2011) suggests that this may be because Gibraltar remains under official British rule and therefore to many seems unworthy of study. The present paper embarked on the task of encapsulating the history of sociolinguistic research in Gibraltar to date. Undertaking this research is of paramount importance, especially in these post-Brexit referendum days when the sociopolitical situation in Gibraltar has become even more complex: although $96 \%$ of Gibraltarians voted to remain in the European Union, it appears that Gibraltar will have to leave the EU together with the United Kingdom. Such events are called Events X by Schneider (2008), defined as moments at which the citizens of a subordinate territory realize that the importance they ascribed to their motherland is not reciprocated. A growing sense of local identity may influence language use and may lead to a shift in the sociolinguistic spectrum among Gibraltarians. The conclusion seems inescapable that a new set of sociolinguistic data must be collected in order to monitor the processes currently taking place in Gibraltar, as they may help uncover not just linguistic, but deeper societal phenomena underway in times of political and social unrest.

\section{References}

Anderson, Benedict. 1991 [1st ed. 1983]. Imagined Communities: Reflections on the Origin and Spread of Nationalism. London and New York: Verso.

Constantine, Stephen. 2013. Community and Identity: The Making of Modern Gibraltar since 1704. Oxford University Press.

Garcia, Joseph. 1994. Gibraltar. Making of a People. Gibraltar: Panorama Publishing.

Garcia, Joseph. 2016. Brexit: A View from Gibraltar. The Round Table 105(5). 585-586.

Howes, H.W. 1964. The Story of Gibraltar. London: Philip \& Tacey Ltd.

Kellermann, Anja. 2001. A New New English: Language, Politics and Identity in Gibraltar. Heidelberg: Books on Demad GmbH.

Kortmann, Bernd and Edgar W. Schneider. 2008. Varieties of English. Berlin: De Gruyter Mouton. Kramer, Johannes. 1986. English and Spanish in Gibraltar. Amsterdam: John Benjamins.

Labov, William. 1963. The social motivation of a sound change. Word 19. 273-309.

Le Page, Robert and Andrée Tabouret-Keller. 1985. Acts of Identity: Creole-Based Approaches to Language and Ethnicity. Cambridge: Cambridge University Press.

Levey, David. 2008. Language Change and Variation in Gibraltar. Amsterdam: John Benjamins.

Melancon, Megan E. 2000. The sociolinguistic situation of Creoles in south Louisiana: identity, characteristics, attitudes. Unpublished Ph.D. dissertation, Louisiana State University.

Milroy, Lesley and Matthew Gordon. 2003. Sociolinguistics: Method and Interpretation. London: Wiley.

Milroy, Lesley. 1987. Language and Social Networks. (2nd ed.). Oxford: Blackwell. 
Moore, Bruce. 2008. Speaking Our Language: The Story of Australian English. Oxford: Oxford University Press.

Moyer, Melissa. 1993. Analysis of Code-switching in Gibraltar. Unpublished Ph.D. dissertation, University of Barcelona.

Poplack, Shana and Marjory Meechan. 1995. Patterns of language mixture: Nominal structure in Wolof-French and Fongbe-French bilingual discourse. In P. Muysken and L. Milroy (eds.), One Speaker, Two Languages, 199-232. Cambridge: Cambridge University Press.

Schreier, Daniel. 2009. Language in Isolation, and Its Implications for Variation and Change. Language and Linguistics Compass 3/2.

Traverso, Albert Austin. 1980. A History of Education in British Gibraltar 1704-1945. (unpublished MA dissertation, University of Southampton).

Weston, Daniel. 2011. Gibraltar's Position in the Dynamic Model of Postcolonial English. English World-Wide 32/3. 338-367. 